\title{
Synthesis and characterizations of degradable aliphatic-aromatic copolyesters from lactic acid, dimethyl terephthalate and diol: Effects of diol type and monomer feed ratio
}

\author{
M. Namkajorn ${ }^{1}$, A. Petchsuk ${ }^{2}$, M. Opaprakasit ${ }^{3}$, P. Opaprakasit ${ }^{1 *}$ \\ ${ }^{1}$ School of Bio-Chemical Engineering and Technology, Sirindhorn International Institute of Technology (SIIT), \\ Thammasat University, Pathum Thani 12121, Thailand \\ ${ }^{2}$ National Metal and Materials Technology Center (MTEC), Pathum Thani 12120, Thailand \\ ${ }^{3}$ Department of Materials Science, Chulalongkorn University, Bangkok 10330, Thailand
}

Received 17 February 2010; accepted in revised form 29 April 2010

\begin{abstract}
Lactic acid-based aliphatic/aromatic copolyesters are synthesized to incorporate the degradability of polylactic acid and good mechanical properties of aromatic species by using polycondensation of lactic acid (LA), dimethyl terephthalate (DMT), and various diols. Effects of diol lengths and comonomer feed ratios on structure and properties of the resulting copolymers are investigated. Three types of diols with different methylene lengths are employed, i.e., ethylene glycol (EG), 1,3-propanediol (PD) and 1,4-butanediol (BD). LA/DMT/diol feed ratios of 2:1:2, 1:1:2, and 1:2:4 are used in each diol system. It is found that types of the diols play an important role in the properties of the copolyester, where an increase in diol length results in an increase in the copolymers molecular weight, and a decrease in $T_{g}, T_{m}$ and crystallinity, when a constant monomer feed ratio is employed. Monomer feed ratio also has a significant effect on properties of the copolymers, where an increase in the aromatic content leads to formation of copolymers with higher molecular weight, longer aromatic block sequence and high aromatic to aliphatic ratio in the chain structure. These, in turn, lead to an increase in $T_{g}, T_{m}$, crystallinity and thermal stability of the copolymer samples, and a reduction in their solubility.
\end{abstract}

Keywords: polymer synthesis, lactic acid, aliphatic/aromatic copolyesters, degradable, diol

\section{Introduction}

Degradable polymers have recently become highly attractive materials in solving the increasingly serious environmental problems due to plastic waste. Current mass-produced petroleum-based polymers are highly resistant to degradation, for example, polyethylene terephthalate (PET), a thermoplastic aromatic polyester that is widely used in the manufacturing of soft-drink bottles. Recycling has been practiced and promoted to reduce the production rate of new polymers. However, this is difficult or inexpedient due to technical and economic consid- erations. One of the promising solutions to this plastic waste problem is to replace conventional plastics in mass use by degradable polymers. Within the new group of degradable polymers, various types of aliphatic polyesters play a major role with respect to industrial relevance [1].

Despite their superior degradability, aliphatic polyesters have some disadvantages in weaker mechanical properties, compared to their aromatic counterparts. Physical and mechanical properties of aliphatic polyesters, however, can be slightly modified by varying their molecular weight or crys- 
tallinity. Incorporation of other groups such as aromatic esters has also proven to provide the materials with a wider range of properties. In contrast, non-degradable aromatic polyesters, such as PET exhibit much better physical and mechanical properties [2]. Recently, incorporation of aliphatic units into aromatic polyesters has been employed in improving the degradability of PET [3-8], poly (propylene terephthalate) (PPT) [3-10], poly(butylene terephthalate) (PBT) $[8,11-12]$, and poly $(1,2-$ propanediyl phthalate) (PPP) [13].

Polylactic acid (PLA) is one of the widely used aliphatic polyesters, due to its environmentallyfriendly properties. Its monomer, lactic acid, is derived from agricultural products, such as starch or sugar. In addition, PLA is proven as a biocompatible material with appreciable mechanical properties comparable to other commodity plastics. However, its low toughness has limited its use in certain applications. In order to improve the mechanical properties of PLA and retain its advantages of degradability, a copolymerization of lactic acid and other aromatic esters has been conducted. Olewnik et al. reported a synthesis and characterization of copolyester from lactic acid and bis(2hydroxyethyl terephthalate) $[14,15]$. In our previous work, lactic acid-based aliphatic/aromatic copolyester was synthesized from dimethyl terephthalate (DMT), lactic acid and ethylene glycol. The copolymer's chemical structure and properties were characterized [16].

In this study, aliphatic/aromatic copolyesters are systematically synthesized from lactic acid (LA), dimethyl terephthalate (DMT), and diols with various methylene lengths. Effects of diols and comonomer feed ratios on structure and properties of the resulting copolymers are investigated. Depending on their chain microstructure and properties, the resulting materials are suitable for a wide range of applications.

\section{Experimental}

\subsection{Materials}

Lactic acid (LA) (88 wt\% aqueous solution) and 3 types of diols: ethylene glycol (EG), 1,3-propanediol (PD) and 1,4-butanediol (BD), were purchased from Carlo Erba (Rodano, Italy) and Acros Organ- ics (Part of Thermo Fischer Scientific, Waltham, MA, USA). Dimethyl terephthalate (DMT) was supplied by Acros. Tin(II) octoate catalyst was provided by Wako Chemicals (Dalton, GA, USA). All chemicals were used without further purification.

\subsection{Synthesis}

The synthesis procedure of the PLA-based aliphatic/aromatic copolyesters is summarized in Figure 1 . The copolymers were polymerized by a polycondensation of LA, DMT, and diols. Three types of diols with different methylene length were employed, i.e. EG, PD and BD. In each synthesis system with specific diol, LA/DMT/diol monomer feed ratios of 2:1:2, 1:1:2 and 1:2:4 were employed. The corresponding copolymers are then coded by the name of diol and the appropriated feed ratio, for example, EG212 refers to a copolymer synthesized from EG diol with a feed ratio of 2:1:2. The synthesis procedure is adopted from our previous work [16]. Essentially, the copolymers were polymerized in a 2-neck round bottom flask under $\mathrm{N}_{2}$ atmosphere at 0.2 mbar. Appropriate amounts of DMT and LA were mixed and stirred at $150^{\circ} \mathrm{C}$ for 1 hour. The mixture was then heated to $200^{\circ} \mathrm{C}$, followed by an addition of half of the corresponding amount of an appropriate diol using a needle injection under $\mathrm{N}_{2}$ atmosphere. The reaction temperature was held at $200^{\circ} \mathrm{C}$ for 2 hours, and then raised to $220^{\circ} \mathrm{C}$ for 1 hour. Next, the remaining excess amount of diol was added and the reaction was further heated for 1 hour. Small-molecular byproducts were finally removed by condensation using a vacuum pump at $220^{\circ} \mathrm{C}$ until the total reaction time reached 7 hours. The resulting copolymers were stored in a desiccator for further characterizations.

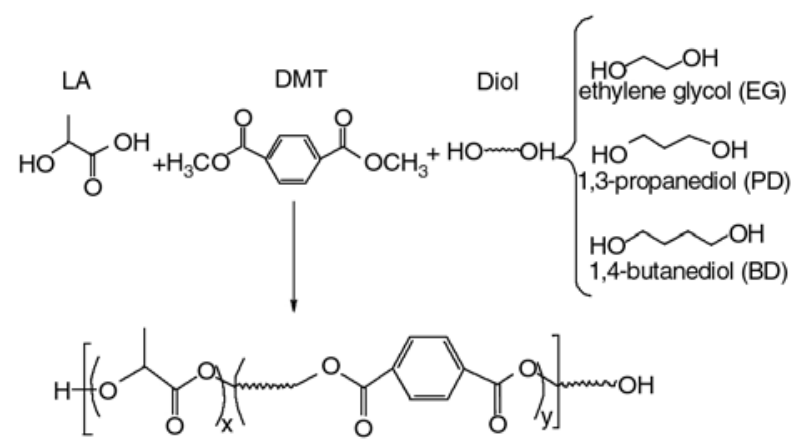

Figure 1. Summary of the synthesis reaction of aliphatic/aromatic copolyesters 


\subsection{Characterizations}

\subsection{1. ${ }^{1}$ H NMR spectroscopy}

${ }^{1} \mathrm{H}$ NMR spectra were recorded on a Bruker AC300 spectrometer by using $7 \%$ wt trifluoroacetic acid/ $\mathrm{CDCl}_{3}$ mixed solvent. The spectrum was recorded immediately in order to avoid end-group esterification by trifluoroacetic acid [17].

\subsubsection{Differential Scanning Calorimetry (DSC)}

DSC analyses were carried out under nitrogen on a DSC 2920 Modulated TA Instruments apparatus equipped with liquid nitrogen cooling accessory, at cooling and heating rates of $20^{\circ} \mathrm{C} / \mathrm{min}$ from 0 to $240^{\circ} \mathrm{C}$ with a sample size of $3-5 \mathrm{mg}$. Glass transition temperatures $\left(T_{g}\right)$ and melting temperatures $\left(T_{m}\right)$ were measured on the second cycle heating curves.

\subsubsection{Thermo Gravimetric Analysis (TGA)}

TGA analyses were carried out under nitrogen on a Mettler Toledo Stare System at a heating rate of $20^{\circ} \mathrm{C} / \mathrm{min}$ from 50 to $1000^{\circ} \mathrm{C}$ using samples of approximately $2.5 \mathrm{mg}$.

\subsubsection{Fourier-Transform Infrared (FTIR) spectroscopy}

FTIR spectra were recorded in transmission mode on a Thermo Nicolet 6700 model spectrometer. 16 scans were coadded, with a resolution of $2 \mathrm{~cm}^{-1}$. The copolymer sample in form of $\mathrm{KBr}$ pellet was prepared by mixing with $\mathrm{KBr}$ powder.

\subsubsection{Solubility test}

Solubility of the copolymer samples was examined in dichloromethane $\left(\mathrm{CH}_{2} \mathrm{Cl}_{2}\right)$ and tetrahydrofuran (THF) at ambient conditions. Essentially, $0.5 \mathrm{~g}$ of sample was dissolved in $10 \mathrm{ml}$ of solvent, and vigorously stirred for 1 hour. The dissoluble portion was then separated from the solution, and its dried weight was recorded. Solubility was calculated on a weight basis.

\section{Results and discussion}

Chemical structure and properties of the resulting copolyesters synthesized from different diols and monomer feed ratios are characterized. Possible sequential structures of the copolymers are summarized in Figure 2. ${ }^{1} \mathrm{H}$ NMR spectra of copolymers derived from the three diol systems at a 2:1:2 monomer feed ratio, and their signal assignments are shown in Figures 3-5. Band assignments of the copolymer derived from EG are similar to those described earlier $[14,16] .{ }^{1} \mathrm{H}$ NMR spectra of the corresponding copolymers synthesized from PD and BD show additional resonances associated with methylene units of diols. Nevertheless, other signals necessary for use in the determination of chain microstructure are similar to those of the EG derived copolyester. The actual terephthalate/lactate (T/L) molar ratios in the chain structure are calculated from the integrations of aromatic proton signals at $8.1 \mathrm{ppm}$ and lactate methines $\left(-\mathrm{CH}\left(\mathrm{CH}_{3}\right)^{-}\right)$ located in the 5.2-5.5 ppm region [16]. Molecular weight $\left(M_{n}\right)$, sequential length $\left(\mathrm{Y}_{(\mathrm{L})}, \mathrm{X}_{(\mathrm{ET})}\right)$, and the degree of randomness of the aromatic/aliphatic

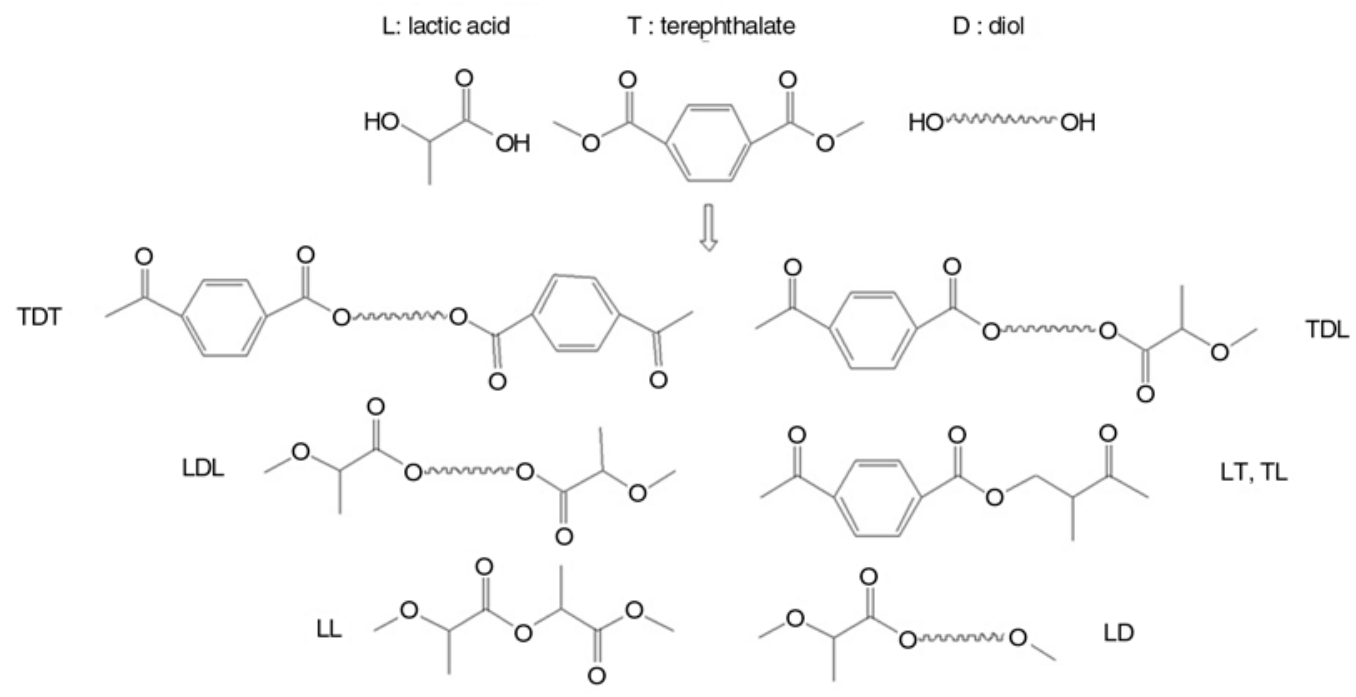

Figure 2. Possible D-centered triads and diads of the resulting copolyesters 


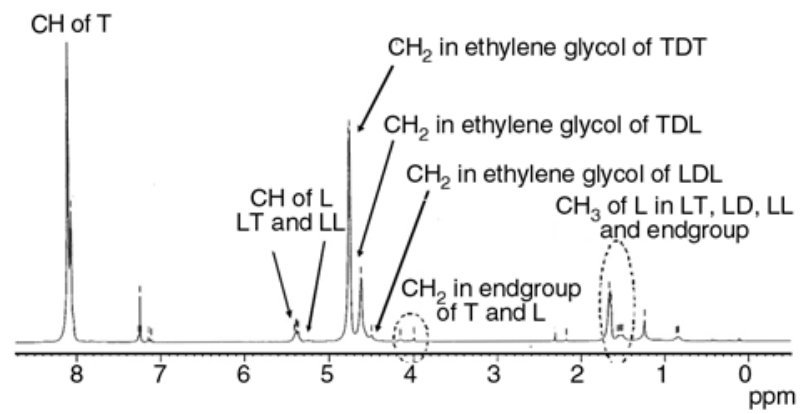

Figure 3. ${ }^{1} \mathrm{H}$ NMR spectrum and signal assignments of EG112

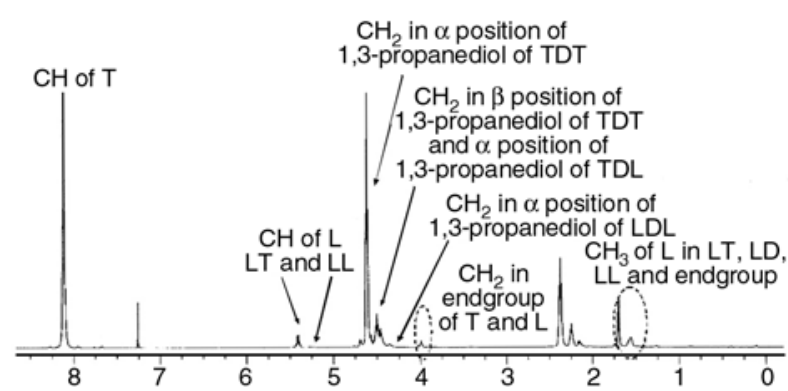

Figure 4. ${ }^{1} \mathrm{H}$ NMR spectrum and signal assignments of PD112

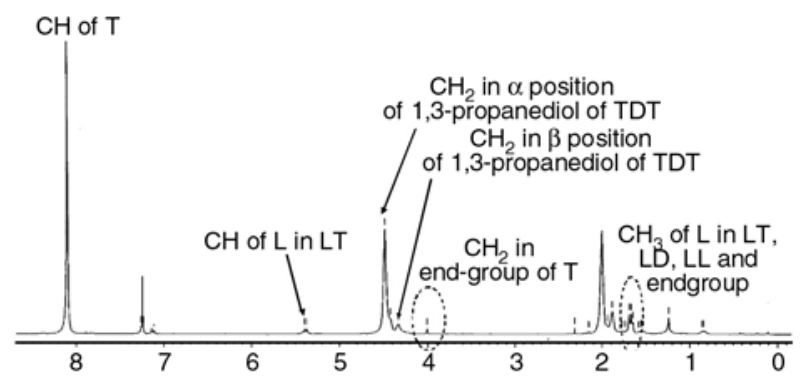

Figure 5. ${ }^{1} \mathrm{H}$ NMR spectrum and signal assignments of BD112

blocks (B) are also calculated from ${ }^{1} \mathrm{H}$ NMR spectra by employing the methodology described elsewhere [14-16,18-20]. Results on chemical structure of the as-synthesized copolyesters are summarized in Table 1, where solubility and thermal properties results are also shown.

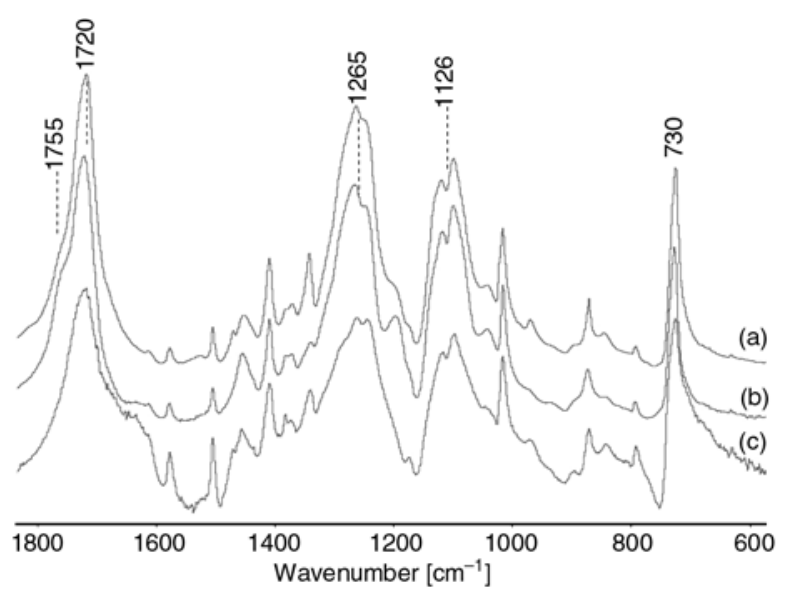

Figure 6. FTIR spectra of copolymers derived from LA/DMT/EG with various monomer feed ratios: 2:1:2 (a), 1:1:2 (b), 1:2:4 (c)

FTIR spectra of copolymers derived from EG at different monomer feed ratios are compared in Figure 6. Band characteristics of aromatic esters are observed at $1720 \mathrm{~cm}^{-1}(\mathrm{C}=\mathrm{O}$ stretching $)$ and $730 \mathrm{~cm}^{-1}$ (ring $\mathrm{C}-\mathrm{H}$ out of plane bending), while the unique $\mathrm{C}=\mathrm{O}$ stretching band of aliphatic units is located at $1755 \mathrm{~cm}^{-1}$. Strong vibrational modes observed at 1265 and $1126 \mathrm{~cm}^{-1}$ are associated with $\mathrm{C}-\mathrm{O}-\mathrm{C}$ asymmetric stretching modes of both aromatic and aliphatic esters. Given these band assignments, aliphatic/aromatic ratios in the copolymer chain structure can be determined from band intensity of the two corresponding $\mathrm{C}=\mathrm{O}$ stretching modes. It is clearly seen that the band intensity ratio is strongly dependent on the monomer feed ratios, reflecting an incorporation of different aromatic/aliphatic ratio in the copolymer chains. This is in good agreement with those observed earlier from NMR results. Additionally, FTIR spectra of copolymers synthesized from other diols (not shown) also exhibit similar characteristics.

Table 1. Results on chain microstructure, thermal properties, and solubility of the copolyesters

\begin{tabular}{|c|c|c|c|c|c|c|c|c|c|}
\hline \multirow{2}{*}{ Copolymers } & \multirow{2}{*}{$\begin{array}{c}\mathbf{M}_{\mathbf{n}^{\mathbf{a}}} \\
{[\mathrm{g} / \mathbf{m o l}]}\end{array}$} & \multicolumn{2}{|c|}{ Sequential lengtha } & \multirow{2}{*}{$\begin{array}{c}\mathrm{T} / \mathrm{L} \\
\text { ratio }^{\mathrm{a}}\end{array}$} & \multirow{2}{*}{$\mathbf{B}^{\mathbf{a}}$} & \multicolumn{2}{|c|}{ Transition temperatures } & \multicolumn{2}{|c|}{ Solubility [\%] } \\
\hline & & $\mathbf{Y}_{(\mathbf{L})}$ & $\mathbf{X}_{(\mathbf{D T})}$ & & & $\mathbf{T}_{\mathrm{g}}\left[{ }^{\circ} \mathbf{C}\right]$ & $\mathbf{T}_{\mathrm{m}}\left[{ }^{\circ} \mathbf{C}\right](\Delta \mathbf{H}[\mathbf{J} / \mathbf{g}])$ & THF & $\mathrm{CH}_{2} \mathrm{Cl}_{2}$ \\
\hline EG212 & 5200 & 2.43 & 0.47 & 1.7 & 2.75 & 44 & - & 97.6 & 95.6 \\
\hline EG112 & 7200 & 1.21 & 3.49 & 3.3 & 4.39 & 58 & $199(28)$ & 15.3 & 44.1 \\
\hline EG124 & 21000 & 1.03 & 7.98 & 5.6 & 6.74 & 76 & $218(30)$ & 0.4 & 11.2 \\
\hline PD212 & 3000 & 1.72 & 2.86 & 1.4 & 2.34 & 20 & $136(18)$ & 83.7 & 88.7 \\
\hline PD112 & 10200 & 1.18 & 4.24 & 6.1 & 7.26 & 29 & $198(43)$ & 5.6 & 14.2 \\
\hline PD124 & 11700 & 1.05 & 8.96 & 13.2 & 14.41 & 31 & $214(53)$ & 0.2 & 4.3 \\
\hline BD212 & 8100 & 1.63 & 2.74 & 1.6 & 2.59 & 32 & $134(18)$ & 72.8 & 86.3 \\
\hline BD112 & 25200 & 1.25 & 9.08 & 5.2 & 5.87 & 26 & $191(37)$ & 1.4 & 10.0 \\
\hline BD124 & 35000 & 1.11 & 18.08 & 15.6 & 15.80 & 31 & $210(42)$ & 1.0 & 1.3 \\
\hline
\end{tabular}

a Calculated from ${ }^{1} \mathrm{H}$ NMR spectra 


\subsection{Effects of diols}

Effects of diols on properties of the copolymers are examined by comparing properties of copolymers derived from the same monomer feed ratio but different diols. The characterization results, as summarized in Table 1, indicate that copolymers synthesized from all three diols show significantly similar length of lactate sequence $\left(\mathrm{Y}_{(\mathrm{L})}\right)$. Interestingly, the application of diols with longer methylene length in its molecule results in formation of copolymers with higher molecular weight and longer diol-terephthalate block sequence $\left(\mathrm{X}_{(\mathrm{DT})}\right)$. This reflects that the nature of diols does not significantly affect the formation of lactate-lactate (L-L) connections, but plays an important role in the incorporation of $\mathrm{D}$ and $\mathrm{T}$ units in the chain structure. This is probably because the longer methylene sequence in bigger size diols provides optimum flexibility and reactivity for their hydroxyl groups to react with acid functional groups of $\mathrm{T}$, resulting in higher extent of polycondensation reaction and hence production of higher MW copolymers. The preference of aromatic-aromatic linkage formation through longer-length diols (T-D-T), compared to that of L-L connection, also results in the production of copolymers with higher $\mathrm{T} / \mathrm{L}$ ratios and longer $\mathrm{T}$ block length in the chain structure, which is reflected by higher degree of deviation from unity of the degree of randomness value (B).

Effects of diols on thermal properties of the copolymers are also summarized in Table 1. Copolymers derived from different diols exhibit glass transition temperature $\left(T_{g}\right)$ at temperatures ranging from 20 to $76^{\circ} \mathrm{C}$. When the same monomer feed ratio is employed, a decrease in $T_{g}$ values is observed in copolymers derived from EG, PD, and BD diols. This is largely due to an increase in their corresponding methylene length, which results in an increase in main chain flexibility of the copolymer structure. It should be noted that the effect of molecular weight on $T_{g}$ is negligible in this comparison, as copolymers derived from the same comonomer feed ratio have comparable molecular weight. The corresponding results also indicate a decreasing trend of $T_{m}$ as a function of increasing diol's length, but with lower degree of $T_{m}$ reduction. This is also due to a variation of chain flexibility inherited from diol's methylene length. Surprisingly, it is observed that T/L ratio does not significantly affect $T_{m}$ of the copolymer, when different diols are employed with a constant feed ratio.

Thermal stability of the copolymers is also examined. TGA thermograms and their $1^{\text {st }}$ derivative traces (DTGA) of copolymers synthesized from different diols with a 1:1:2 feed ratio are shown in Figure 7. The results show that PD112 and BD112 have significantly comparable degradation temperature $\left(T_{d}\right)$ at $415^{\circ} \mathrm{C}$. EG112, however, shows better thermal stability with a main degradation step taking place at $450^{\circ} \mathrm{C}$. The EG112 copolymer also has higher remaining mass at a temperature higher than $450^{\circ} \mathrm{C}$, compared to PD112 and BD112. These are probably due to aromatic fractions containing T-D-T sequences, where T-EG-T is more stable than those of T-PD-T or T-BD-T as a result from the less flexibility of EG segments. In addition, a separate degradation step associated with aliphatic $\mathrm{L}-\mathrm{L}$ sequences is clearly observed at $380^{\circ} \mathrm{C}$ in DTGA traces of EG112, while those of PD112 and BD112 are enveloped in the main degradation step of aromatic constituent.

Results from solubility testing indicate that all copolymers have higher solubility in $\mathrm{CH}_{2} \mathrm{Cl}_{2}$, compared to that in THF, reflecting a closer match of the solvent and copolymer solubility parameters. It is clearly observed that copolymers with lower $\mathrm{T}$ content in the chain structure exhibit higher solubility in both solvents, due to the hydrophobicity of TD units in the chain compared to that of the

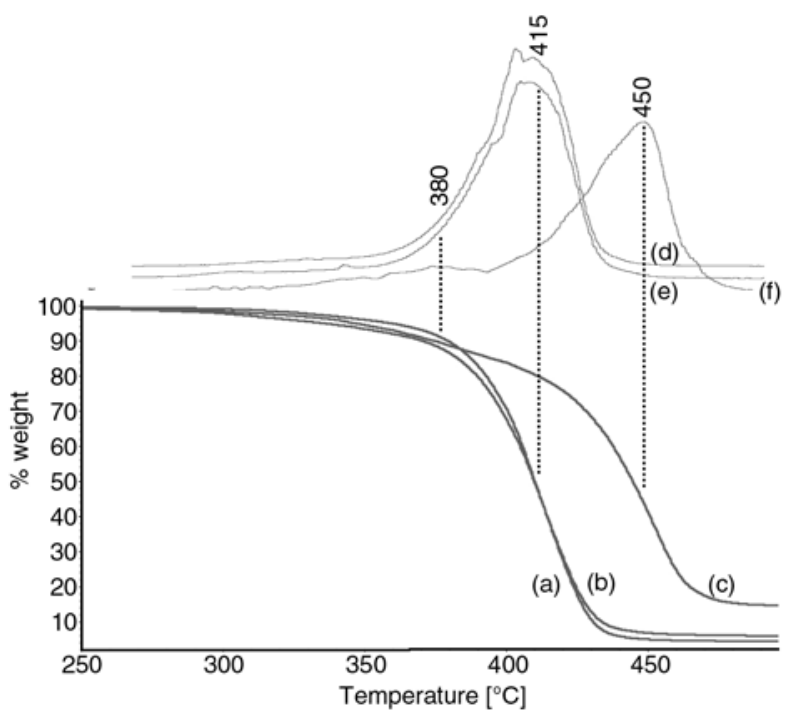

Figure 7. TGA thermograms of copolymers synthesized from different diols with a 1:1:2 feed ratio: $\mathrm{BD}$ (a), PD (b), EG (c), and their corresponding DTGA traces: BD (d), PD (e), EG (f) 
L sequence. It should also be noted that shorter chain length may also result in the higher solubility of the samples.

\subsection{Effects of monomer feed ratios}

Results on properties of the copolyesters also indicate that the degree of polymerization and chain microstructure of the copolymer are strongly dependent on the monomer feed ratios, where higher molar mass polymers are produced when a feed ratio with higher aromatic content is employed. This is probably due to the relatively higher reactivity of $-\mathrm{OH}$ functional and carboxyl groups from diols and DMT, to undergo transesterification, compared to that of the corresponding groups present in lactic acid monomers. It is noted that the feed content of diol is kept at 2 equivalent moles with respect to that of the aromatic content, as it was observed in our early work that an excess amount of diol was required to compensate for diol loss during a vacuum condensation process [16]. The results also suggest that a decrease in sequential length of lactate, $Y_{(L)}$, and an increase in that of its aromatic sequence counterpart, $\mathrm{X}_{(\mathrm{DT})}$, in the copolymer chain is observed upon increasing of aromatic content in feed. This is in concert with an increase in the degree of randomness (B), indicating higher block characteristics. The increase in aromatic block length consequently results in an increase in the T/L ratios in the copolymer chain upon increasing the aromatic content in feed.

Effect of the monomers feed ratios on thermal properties of the copolymers is also examined. It is observed that all samples exhibit melting characteristics, reflecting that these copolymers are semicrystalline in nature, except that derived from EG at a feed ratio of 2:1:2. The absence of a $T_{m}$ peak in this sample is partly due to its low molecular weight and its shorter aromatic sequence than the aliphatic sequential units in the chain structure, i.e. $\mathrm{X}_{(\mathrm{DT})}$ and $\mathrm{Y}_{(\mathrm{L})}$ of 0.47 and 2.43 (see Table 1). The relatively longer aromatic sequence is therefore essential for the copolymers to exhibit crystalline behavior. As expected, the results indicate that copolymers synthesized from a 1:2:4 feed ratio show the highest $T_{m}$, and $T_{g}$ values. In addition, an increase in $T_{g}, T_{m}$ and crystallinity (calculated from $\Delta H$ ) with an increase in aromatic content in monomer feed ratio is observed. This is partly due to the higher aromatic content in the chain and the longer aromatic block length, and the higher molecular weight of the copolymers.

TGA and DTGA traces of copolymers synthesized from PD with different feed ratios are shown in Figure 8. Thermal degradation of 'short' aliphatic L-L sequences, i.e. L-L units located next to T units, in all 3 samples is observed at $380^{\circ} \mathrm{C}$. PD212, however, shows another separate degradation mechanism at $305^{\circ} \mathrm{C}$ with approximately $25 \%$ wt loss, which is higher than the mass loss of aliphatic domains of the other two samples. This is probably due to 'longer' L-L sequences in PD212 copolymer. The shortening of aliphatic sequences in the chain structure results in higher aliphatic-aromatic attachments, leading to higher thermal stability of the aliphatic sequences. Nevertheless, the mechanism of the degradation due to aromatic domains observed at $T_{d}=415^{\circ} \mathrm{C}$, and the remaining weight at a temperature higher than $450^{\circ} \mathrm{C}$ of all samples are comparable. This indicates that thermal stability of aromatic domains is independent on the monomer feed ratio.

Solubility of the copolymers in THF and $\mathrm{CH}_{2} \mathrm{Cl}_{2}$ solvents shows a decreasing trend upon increasing of aromatic content in feed. Upon closer examination of copolymers derived from a specific diol but different feed ratios, it is observed that the reduction of solubility in the two solvents is closely correlated to an increase in molecular weight, aromatic content, aromatic block length or crystallinity of

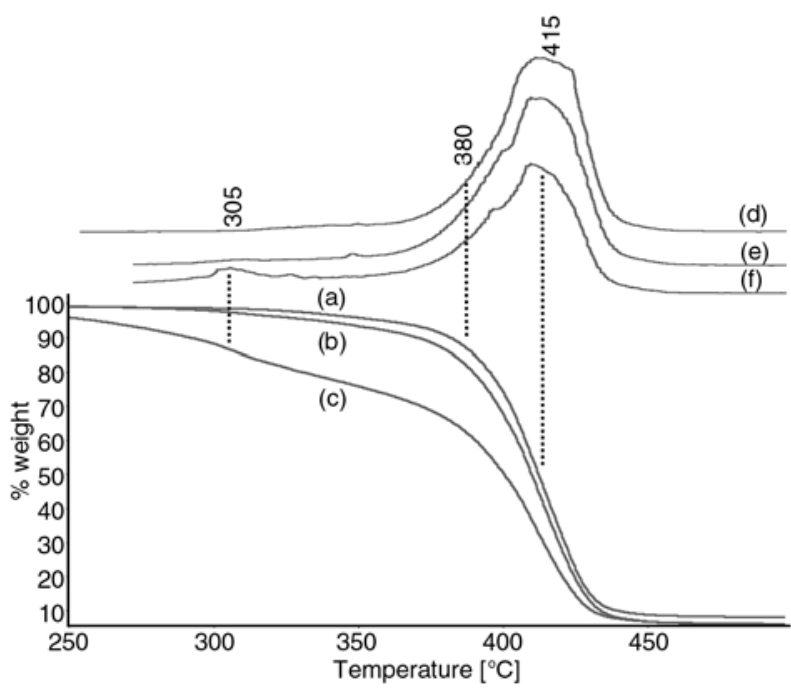

Figure 8. TGA thermograms of copolymers derived from $\mathrm{PD}$ at different monomer feed ratios feed ratios: 1:2:4 (a), 1:1:2 (b), 2:1:2 (c), and their corresponding DTGA traces: 1:2:4 (d), 1:1:2 (e), $2: 1: 2$ (f) 
the copolymers, which result from an increase in the aromatic content in the monomer feed ratio.

\section{Conclusions}

Aliphatic-aromatic copolyesters are systematically synthesized from lactic acid, dimethyl terephthalate and various diols. Results on effects of diols on properties of the copolyesters indicate that 1,4butanediol provides copolymers with highest molecular weight, compared to that of shorterchain diols, due to its optimum methylene flexibility and the reactivity of hydroxyl groups with acid functional groups. Types of diol and aromatic/ aliphatic content in the copolymer chain play a key role in glass transition behaviors of the samples by imposing different degree of chain flexibility. In addition, molecular weight, relative length and relative content of aromatic/aliphatic sequences in the chain structure are essential parameters to govern crystalline behaviors, thermal stability, and solubility of the copolymers.

Monomer feed ratio also has a significant effect on properties of the copolymers, where an increase in the aromatic content leads to formation of copolymers with higher molecular weight, longer aromatic block sequences and high aromatic to aliphatic ratio, in the chain structure. These, in turn, lead to an increase in $T_{g}, T_{m}$, crystallinity and thermal stability of the copolymer samples, and a reduction in their solubility. Properties of these lactic acid/terephthalate-based copolyesters can be fine tuned by varying these two preparation conditions for use in specific applications.

\section{Acknowledgements}

Financial support of this work is provided by The Thailand Research Fund (TRF) and The Commission on Higher Education (CHE), under grant no. RSA5280029. M. Namkajorn is partially supported by The National Science and Technology Development Agency (NSTDA) and Sirindhorn International Institute of Technology (SIIT), Thammasat University.

\section{References}

[1] Awaja F., Pavel D.: Injection stretch blow moulding process of reactive extruded recycled PET and virgin PET blends. European Polymer Journal, 41, 26142634 (2005).

DOI: $10.1016 /$ j.eurpolymj.2005.05.036
[2] Ki H. C., Park O. O.: Synthesis, characterization and biodegradability of the biodegradable aliphatic-aromatic random copolyesters. Polymer, 42, 1849-1861 (2001).

DOI: $\underline{10.1016 / \mathrm{S} 0032-3861(00) 00466-3}$

[3] Gilding D. K., Reed A. M.: Biodegradable polymers for use in surgery-poly(ethylene oxide) poly(ethylene terephthalate) (PEO/PET) copolymers: 1. Polymer, 20, 1454-1458 (1979).

DOI: 10.1016/0032-3861(79)90008-9

[4] Reed A. M., Gilding D. K.: Biodegradable polymers for use in surgery- poly(ethylene oxide)/poly(ethylene terephthalate) (PEO/PET) copolymers: 2. In vitro degradation. Polymer, 22, 499-504 (1981). DOI: $10.1016 / 0032-3861(81) 90169-5$

[5] Kitotsukuri T., Masuda T., Tsutsumi N., Sakai W., Nagata M.: Poly(ethylene terephthalate) copolymers with a smaller amount of poly(ethylene glycol)s and poly(butylene glycol)s. Polymer, 36, 2629-2635 (1995).

DOI: $10.1016 / 0032-3861(95) 91211-\mathrm{O}$

[6] Heidary S., Gordon B.: Hydrolyzable poly(ethylene terephthalate). Journal of Polymers and the Environment, 2, 19-26 (1994). DOI: $10.1007 / \mathrm{BF} 02073483$

[7] Nagata M., Kitotsukuri T., Minami S., Tsutsumi N., Sakai W.: Enzymatic degradation of poly(ethylene terephthalate) copolymers with aliphatic dicarboxylic acids and/or poly(ethylene glycol). European Polymer Journal, 33, 1701-1705 (1997). DOI: $10.1016 / \mathrm{S} 0014-3057(97) 00063-3$

[8] Witt U., Müller R-J., Deckwer W-D.: Biodegradation behavior and material properties of aliphatic/aromatic polyesters of commercial importance. Journal of Polymers and the Environment, 5, 81-89 (1997). DOI: $10.1007 / \mathrm{BF} 02763591$

[9] Witt U., Müller R-J., Augusta J., Widdecke H., Deckwer W-D.: Synthesis, properties and biodegradability of polyesters based on 1,3-propanediol. Macromolecular Chemistry and Physics, 195, 793-802 (1994). DOI: $10.1002 / \mathrm{macp} .1994 .021950235$

[10] Witt U., Müller R-J., Deckwer W-D.: Biodegradation of polyester copolymers containing aromatic compounds. Journal of Macromolecular Science Part A: Pure and Applied Chemistry, 32, 851-856 (1995). DOI: $10.1080 / 10601329508010296$

[11] Witt U., Müller R-J., Deckwer W-D.: New biodegradable polyester-copolymers from commodity chemicals with favorable use properties. Journal of Environmental Polymer Degradation, 3, 215-223 (1995). DOI: $\underline{10.1007 / \mathrm{BF} 02068676}$

[12] Marten E., Müller R-J., Deckwer W-D.: Studies on the enzymatic hydrolysis of polyesters. II. Aliphatic-aromatic copolyesters. Polymer Degradation and Stability, 88, 371-381 (2005).

DOI: 10.1016/j.polymdegradstab.2004.12.001 
[13] Valiente N., Lalot T., Brigodiot M., Maréchal E.: Enzymic hydrolysis of phthalic unit containing copolyesters as a potential tool for block length determination. Polymer Degradation and Stability, 61, 409-415 (1998).

DOI: 10.1016/S0141-3910(97)00226-7

[14] Olewnik E., Czerwinski W., Nowaczyk J., Sepulchre M. O., Tessier M., Salhi S., Fradet A.: Synthesis and structural study of copolymers of L-lactic acid and bis(2-hydroxyethyl terephthalate). European Polymer Journal, 43, 1009-1019 (2007).

DOI: $10.1016 / j$. eurpolymj.2006.11.025

[15] Olewnik E., Czerwinski W., Nowaczyk J.: Hydrolytic degradation of copolymers based on L-lactic acid and bis-2-hydroxyethyl terephthalate. Polymer Degradation and Stability, 92, 24-31 (2007).

DOI: $10.1016 /$ j.polymdegradstab.2006.10.003

[16] Opaprakasit M., Petchsuk A., Opaprakasit P., Chongprakobkit S.: Effects of synthesis conditions on chemical structures and physical properties of copolyesters from lactic acid, ethylene glycol and dimethyl terephthalate. Express Polymer Letters, 3, 458-468 (2009). DOI: 10.3144/expresspolymlett.2009.56
[17] Kenwright A. M., Peace S. K., Richards R. W., Bunn A., MacDonald W. A: End group modification in poly(ethylene terephthalate). Polymer, 40, 2035-2040 (1999).

DOI: $\underline{10.1016 / \mathrm{S} 0032-3861(98) 00433-9}$

[18] Tessier M., Fradet A.: Determination of the degree of randomness in condensation copolymers containing both symmetrical and unsymmetrical monomer units: A theoretical study. e-Polymers, no.30 (2003).

[19] Grzebieniak K.: Copolyesters of ethylene terephthalate and lactic acid susceptible to hydrolytic degradation. Fibres and Textiles in Eastern Europe, 4, 34-37 (1996).

[20] Grzebieniak K., Ratajska M., Strobin G.: Estimation of hydrolysis and biodegradation processes in ethylene terephthalate and lactic acid copolymers. Fibres and Textiles in Eastern Europe, 9, 61-65 (2001). 